\title{
Coronavirus disease 2019 (COVID-19) treatment versus mycobacterial infections: Better safe than sorry?
}

\author{
Henry Marcel Zalona Fernandes MSc ${ }^{1}$ (1), Gabriela Mastrobuono $\mathrm{MSc}^{1}$, Emilyn Costa Conceição $\mathrm{PhD}^{2,3}$ (1), \\ Rubens Clayton da Silva Dias $\mathrm{PhD}^{4}$ (1), Daniela Sales Alviano $\mathrm{PhD}^{1}$ (1) and Rafael Silva Duarte MD, $\mathrm{PhD}^{1}$ (1) \\ ${ }^{1}$ Institute of Microbiology, Federal University of Rio de Janeiro, Rio de Janeiro, Brazil, ${ }^{2}$ Laboratory of Bacteriology and Bioassays, National Institute of \\ Infectology Evandro Chagas, Oswaldo Cruz Foundation, Rio de Janeiro, Brazil, ${ }^{3}$ Postgraduate Program in Clinical Research of Infectious Diseases, National \\ Institute of Infectology Evandro Chagas, Oswaldo Cruz Foundation, Rio de Janeiro, Brazil and ${ }^{4}$ Biomedical Institute, Federal University of State of Rio de Janeiro, \\ Rio de Janeiro, Brazil
}

To the Editor-More than 1 year after the onset of the coronavirus disease 2019 (COVID-19) pandemic, severe acute respiratory coronavirus virus 2 (SARS-CoV-2) has infected $\sim 113$ million people and has caused $\sim 2.5$ million deaths, according to the World Health Organization (WHO). Vaccination campaigns have been implemented in several countries worldwide as a prevention strategy for preventing new cases, preventing overcrowding of health facilities and decreasing COVID-19-associated deaths. Nevertheless, the total number of vaccines produced is still not sufficient to address the world population, especially developing countries, and many people continue to be infected daily, requiring hospitalization and health care. ${ }^{1}$

Currently, there is no effective treatment for COVID-19. However, some drugs and immunomodulators agents have been suggested to prevent the aggravation of clinical conditions: azithromycin, hydroxychloroquine, remdesivir, lopinavir, ritonavir, dexamethasone, tocilizumab, and others. ${ }^{2}$ Previous studies have also alluded to the importance of differential diagnosis to facilitate adequate treatment because other infectious lung diseases, such as tuberculosis (TB) and nontuberculous mycobacteria (NTM) pulmonary diseases, may present similar symptoms and result in increased disease severity if they are not correctly identified early. ${ }^{3}$ Furthermore, TB-COVID-19 and NTM-COVID-19 coinfections have also been described. ${ }^{3,4}$ Some medications used in COVID-19 therapy can cause drugdrug interactions with first-line anti-TB drugs, such as antivirals and corticosteroids with rifampicin, ${ }^{5,6}$ or they can increase the risk of latent TB reactivation and NTM pulmonary diseases, such as antirheumatic and immunomodulatory agents. ${ }^{7,8}$ In addition, azithromycin, which has been adopted in the medication management of COVID-19 patients based on its anti-inflammatory and antiviral properties, may result in the development of macrolide-resistant mycobacterial strains (Table 1). ${ }^{9}$

Therefore, when COVID-19 is suspected, differential diagnoses should be performed to prevent risk factors for mycobacterial disease due to inadequate patient treatment. On the other hand, patients with concomitant mycobacterial and COVID-19 etiology require simultaneous treatment, but coadministration

Author for correspondence: Henry Marcel Zalona Fernandes M.Sc., E-mail: henry_zalona@hotmail.com.

Cite this article: Zalona Fernandes HM, et al. (2022). Coronavirus disease 2019 (COVID-19) treatment versus mycobacterial infections: Better safe than sorry?. Infection Control \& Hospital Epidemiology, 43: 952-953, https://doi.org/10.1017/ ice.2021.124 of rifampicin with antiviral drugs (eg, remdesivir, lopinavir and ritonavir) should be avoided due to the gastrointestinal and liver toxicity risk in addition to the reduction of antivirals drugs to subtherapeutic concentrations. ${ }^{6}$ In a related study, high cortisol levels have been proposed as a possible prognostic marker for COVID-19 associated with adverse outcomes. However, concomitant use of rifampicin with dexamethasone can result in increased dexamethasone metabolism and altered cortisol levels. ${ }^{5,10}$ Under these circumstances, an antimycobacterial protocol should be maintained to reduce the selection of resistant mycobacterial strains, and drug therapy for COVID-19 should be limited to severe cases. ${ }^{3}$

During the COVID-19 pandemic, TB surveillance programs have also been affected by social isolation and limited patient access to health services, resulting in delayed diagnosis and treatment failure. Moreover, COVID-19 and TB share socioeconomic determinants and comorbidities, so TB-COVID-19 coinfection should be considered, especially in endemic regions, because it can result in potentiated pathogenesis of both diseases and consequent worsening of the patient's condition. Some measures that may be used in pandemic management to improve TB monitoring include assessing patient and family exposure history and implementing digital health-assistive technologies. ${ }^{3}$

Due to the absence of specific treatment of COVID-19, only ongoing drug trials have been used to improve the outcomes of hospitalized patients. Nevertheless, drug therapy protocols for COVID-19 can increase susceptibility to mycobacterial infections. $^{3,4}$ Thus, further studies analyzing the therapeutic agents used for COVID-19 and their influence on mycobacterial viability and virulence are needed. Their findings will contribute to clinical decision making regarding the best treatment strategy while preventing the development of mycobacterial infections or serious complications in TB-COVID-19 and NTMCOVID-19 coinfections, especially in elderly patients with comorbidities and in TB-endemic countries, such as Brazil and India, which are among the 3 countries with the highest burden of COVID-19 worldwide. .,3 $^{1}$

Acknowledgments. The authors acknowledge support from Foundation for Research Support of the State of Rio de Janeiro (FAPERJ) and National Council for Scientific and Technological Development (CNPq).

Financial support. This study was supported by the Coordenação de Aperfeiçoamento de Pessoal de Nível Superior, Brazil (CAPES, finance code 001).

Conflicts of interest. All authors report no conflicts of interest relevant to this article. 
Table 1. Therapeutic Suggested Approaches for COVID-19 and Possible Risk Factors for Mycobacterial Diseases

\begin{tabular}{|c|c|c|c|c|}
\hline Therapeutic Agent & $\begin{array}{l}\text { Pharmacological } \\
\text { Class }\end{array}$ & Proposed Mechanism of Action in COVID-19 & $\begin{array}{l}\text { Risk Factors for Mycobacterial } \\
\text { Disease }\end{array}$ & Reference \\
\hline Azithromycin & Antibiotic & Immunomodulatory properties and in vitro antiviral activity & $\begin{array}{l}\text { Potential emergence of macrolide- } \\
\text { resistant NTM }\end{array}$ & 9 \\
\hline Hydroxychloroquine & Antirheumatic & Anti-inflammatory action and preventing viral entry into the cell & Increased risk of NTM disease & 7 \\
\hline Remdesivir & Antiviral & Inhibition of RdRp, preventing viral RNA synthesis & $\begin{array}{l}\text { Drug-drug interaction with } \\
\text { rifampicin }\end{array}$ & 6 \\
\hline Lopinavir & Antiviral & Protease inhibitory activity, preventing viral replication & $\begin{array}{l}\text { Drug-drug interaction with } \\
\text { rifampicin }\end{array}$ & 6 \\
\hline Ritonavir & Antiviral & Protease inhibitory activity, preventing viral replication & $\begin{array}{l}\text { Drug-drug interaction with } \\
\text { rifampicin }\end{array}$ & 6 \\
\hline Dexamethasone & Corticosteroid & $\begin{array}{l}\text { Anti-inflammatory and immunosuppressive properties, } \\
\text { preventing cytokine storm and damage to lung tissue }\end{array}$ & $\begin{array}{l}\text { Drug-drug interaction with } \\
\text { rifampicin }\end{array}$ & 5 \\
\hline Anakinra & Immunomodulator & $\begin{array}{l}\text { Blocking IL-1 signaling, preventing cytokine storm and damage } \\
\text { to lung tissue }\end{array}$ & Reactivation of latent TB & 8 \\
\hline Canakinumab & Immunomodulator & $\begin{array}{l}\text { Blocking IL-1 signaling, preventing cytokine storm and damage } \\
\text { to lung tissue }\end{array}$ & Reactivation of latent TB & 8 \\
\hline Tocilizumab & Immunomodulator & $\begin{array}{l}\text { Blocking IL-6 signaling, preventing cytokine storm and damage } \\
\text { to lung tissue }\end{array}$ & $\begin{array}{l}\text { Increased risk of NTM disease and } \\
\text { reactivation of latent TB }\end{array}$ & 8 \\
\hline Ruxolitinib & Immunomodulator & $\begin{array}{l}\text { JAK1 and JAK2 inhibition, preventing cytokine storm and } \\
\text { damage to lung tissue }\end{array}$ & $\begin{array}{l}\text { Increased risk of NTM disease and } \\
\text { reactivation of latent TB }\end{array}$ & 8 \\
\hline
\end{tabular}

Note. NTM, non-tuberculous mycobacteria; TB, tuberculosis; RdRp, RNA-dependent RNA polymerase; IL, interleukin; JAK, Janus kinases.

\section{References}

1. Weekly operational update on COVID-19-1 March 2021. World Health Organization website. https://www.who.int/publications/m/item/weeklyoperational-update-on-covid-19-1-march-2021. Updated March 1, 2021. Accessed March 3, 2021.

2. Magro, G. COVID-19: review on latest available drugs and therapies against SARS-CoV-2. Coagulation and inflammation cross-talking. Virus Res 2020, doi: 10.1016/j.virusres.2020.198070.

3. Crisan-Dabija R, Grigorescu C, Pavel CA, et al. Tuberculosis and COVID-19: lessons from the past viral outbreaks and possible future outcomes. Can Respire J 2020. doi: 10.1155/2020/1401053.

4. Rodriguez JA, Bonnano C, Khatiwada P, Roa AA, Mayer D, Eckardt PA. COVID-19 coinfection with Mycobacterium abscessus in a patient with multiple myeloma. Case Rep Infect Dis 2021. doi: 10.1155/2021/8840536.

5. Abdullah HN, Nowalid WKWM. Abnormal dexamethasone suppression tests in a rifampicin-treated patient with suspected Cushing's syndrome. Endokrynol Pol 2010;61:706-709.
6. Lemaitre F, Solas C, Grégoire M, et al. Potential drug-drug interactions associated with drugs currently proposed for COVID-19 treatment in patients receiving other treatments. Fundam Clin Pharmacol 2020; 34:530-547.

7. Brode SK, Jamieson FB, Ng R, et al. Increased risk of mycobacterial infections associated with anti-rheumatic medications. Thorax 2015;70: 677-682.

8. Kordzadeh-Kermani E, Khalili H, Karimzadeh I, Salehi M. Prevention strategies to minimize the infection risk associated with biologic and targeted immunomodulators. Infect Drug Resist 2020;13:513.

9. Choi H, Kim SY, Lee H, et al. Clinical characteristics and treatment outcomes of patients with macrolide-resistant Mycobacterium massiliense lung disease. Antimicrob Agents Chemother 2017;61(2):e02189-16.

10. Tan T, Khoo B, Mills EG, et al. Cortisol concentrations and mortality from COVID-19-authors' reply. Lancet Diabetes Endocrinol 2020;8: 809-810.

\title{
Implications of social distancing in Brazil in the COVID-19 pandemic
}

\author{
Raquel Cristina Cavalcanti Dantas $\mathrm{PhD}^{1}$ (1), Paola Amaral de Campos $\mathrm{PhD}^{2}$, Iara Rossi $\mathrm{MSc}^{2}$ and \\ Rosineide Marques Ribas PhD $^{2}$ \\ ${ }^{1}$ Institute of Biotechnology, Federal University of Uberlandia, Brazil and ${ }^{2}$ Laboratory of Molecular Microbiology, Federal University of Uberlandia, Brazil
}

\footnotetext{
Author for correspondence: Rosineide Marques Ribas, E-mail: rosi_ribas@yahoo. com.br

Cite this article: Dantas RCC, et al. (2020). Implications of social distancing in Brazil in the COVID-19 pandemic. Infection Control \& Hospital Epidemiology, 43: 953-954, https:// doi.org/10.1017/ice.2020.210
}

To the Editor-The pandemic caused by a novel coronavirus disease, known as COVID-19, carried millions of people around the world to a state of unprecedented panic. The World Health Organization (WHO) stated that more than one-third of the world is currently under some social distancing pattern, which is the 